connecting two temporary buildings" to house the 23,000 manila envelopes containing the questionnaires. The findings of the Oxford Survey met with some opposition at a time when X-rays were routinely used for such things as measuring feet in shoe shops. However, they were eventually upheld by large-scale, long-term studies, leading finally to official recommendations against taking $\mathrm{X}$-rays of a fetus.

But who was Alice Stewart, and how did she come to be in Oxford in the first place, choosing between clinical medicine and epidemiology? Gayle Greene provides us with an extended account of the events leading to this juncture in her life. She starts with the story of Stewart's mother, who in 1897 came to London from Scarborough in Yorkshire to study medicine, married a pioneering paediatrician and moved to Harrogate with the intention of practising medicine together with her husband. There is a touching account of them putting their professional name-plates up together, and incurring the wrath of a senior member of their Harrogate practice who did not wish his practice to be tainted by the presence of a female physician. Stewart's parents later bought their own practice in Sheffield, had eight children, and became deeply involved in welfare and the general reform of medical practice.

Eventually, the couple's career paths diverged, as Stewart's father qualified as a consultant physician, which by law prevented her mother from engaging in general practice. Instead, she took a position as a doctor in an armament factory and as 'Lady Tutor in Anatomy' at Sheffield Medical School.

Greene effectively links the early events in Stewart's life - growing up in these particular circumstances - to her indefatigable quest for intellectual stimulation and the terms of her independence in her life and work. From early days, she had been attuned to the trade-off between fighting her corner and finding fulfilment within the boundaries of compromise. In the 30 years of her life spent in Oxford, rather than seeking to further her status within the university, Stewart chose to accommodate herself within a "crack in the system" and get on with her work. Hers is the story of a proud woman, but one clever enough to place her pride outside the boundaries of institution, so that the repression she encountered did nothing to diminish her enthusiasm for life. Part of her extraordinary self-confidence appears to derive from her outstanding record in clinical medicine. "Now, I must tell you as a physician I was a tremendous snob," she tells Greene. Success in a different discipline, it appears, gave her the strength and courage to negotiate her position in a new field.

Greene is careful to point out the privileges of Stewart's background as well as the difficult experiences that equipped her for a life in science. She was educated at a

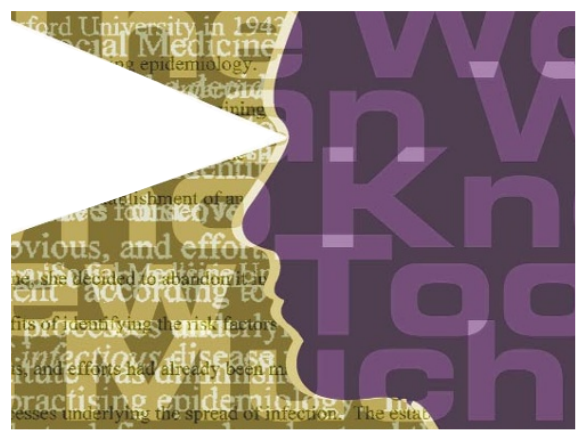

progressive public school, and came to Cambridge already integrated into a "charmed inner circle ... of beautiful well groomed young women". She married a fellow student at Cambridge who became a French master at Harrow School, and for a while she played the role of wife and mother. In the meantime, she hoisted herself out of a low-key research job at the London School of Tropical Medicine and Hygiene into full-time clinical medicine. She sat for her membership of the Royal College of Physicians and succeeded in her first attempt, and in 1939 was appointed to a consultant post.

Juggling a successful career, children and the demands of being a staff wife might have been the entire shape of Stewart's life had it not been for the Second World War. Stewart was asked to replace a senior assistant at the Nuffield Hospital in Oxford who had been called up for service. "It was the sort of job that was normally never open to women," says Stewart.

The quality of her life before the war and during her years in Oxford does little to substantiate the suggestion of persecution in the title of the book. It is only in the latter part of the book that we begin to identify with the sinister ring of the title, when Greenelays bare the extraordinary history of resistance by the US government to the progress of research on the hazards of radiation. Stewart's place in this scenario was as a proponent of the notion that sustained exposure to low-level radiation carries an increased risk of cancer. She became vocal in this post-retirement period of her life in supporting the various researchers who had been isolated by this process of "governmental interference". She began to serve regularly as an expert witness in compensation cases, and engaged at an international level in the public debate about nuclear safety.

In Britain, she participated in the Windscale, Sizewell and Dounreay inquiries and acted as an expert witness in the trial of the 44 women who had danced on the missile silo at Greenham Common. While not entirely comfortable with her position as a hero among activists, Stewart declares that she has "a responsibility as a scientist and physician to support them". Suddenly, she is no longer content with being invisible.

Greene attempts to comment on this change from the perspectives of gender and marginalization, and ends up with a rather diffuse amalgam of quotations and impressions. However, one clear message emerges: it can work for a time to plough on quietly, engirdled and protected by your self-esteem, but it is hard to make the same choice when your silence quite obviously affects the lives of others.

Sunetra Gupta is at the Wellcome Centre for Infectious Disease Epidemiology, University of Oxford, South Parks Road, Oxford OX1 3PS, UK.

\section{• Of science and men}

The Genius of Science: A Portrait Gallery of 20th Century Physicists by Abraham Pais

Oxford University Press: 2000. 364 pp. $£ 25, \$ 30$

\section{Giovanni F. Bignami}

Having paid compulsory tribute to the Medicis, the Grand Dukes of Tuscany, Giorgio Vasari dedicates his monumental opus, Lives of the Most Excellent Painters, Sculptors and Architects (Giunti, Florence, 1568), to his fellow artists. Vasari was a great biographer of the artists of the Italian Renaissance. In 1,012 quarto pages, with illustrations, he turned their life stories into gripping tales. He could do this because he was one of them, a famous artist in his own right, for whom Michelangelo drew fresco cartoons. He was also a magnificent writer.

Not all biographers had such a style. Plutarch and Tacitus, who wrote biographies of the great men of the first century, were not emperors themselves, although they obviously moved in the right circles - Tacitus, for example, was the son-in-law of Emperor Agricola. We read (or are forced to study) their works, admire their heroes, and learn. In the case of Vasari, however, there's much more. We are transported into the minds and hands of great artists, and sit transfixed as we watch the unfolding of both history and genius - an apt comparison, I think, for the newly published work of Abraham 'Bram' Pais, albeit one he himself would not make.

Pais is a scientist of world class, and he has obviously been moving in the right circles for quite a few years now. $\mathrm{He}$, too, has Vasari's capacity for making his biographees jump out of the page, both in his more extended works (like his famous ones on Albert Einstein and Niels Bohr) and within the 'microbiography' genre which he himself, I submit, invented.

Pais is the man who can say that he knows "so well" the article that Bohr wrote for Einstein's seventieth birthday (1949), because "I helped him prepare it"; or the personal recollection of Paul Dirac (Nobel prizewinner at 
31), and his invention of the 'bra' (the left half of an expression contained within a bracket); or his referring to transformation theory as "my darling".

And when did Pais first meet Wolfgang Pauli? At a 1946 party in Bohr's home, of course. The whole chapter on Pauli is so engrossing as to become unstoppable, even troubling reading: how could Pauli in 1921 (aged only 21) publish a review of the relativity theory that was so good as to merit Einstein's praise? Easy: he started early, during the boring hours at the Gymnasium, when he surreptitiously read Einstein's papers under his desk. We follow the development of Pauli's thoughts on physics, notably on quantum physics and the relations between spin and quantum statistics. A lifelong interest of his, whichled to that pillar of physics known as the spin-statistics theorem, was, sadly, to be formulated only in 1958, the year of Pauli's death.

Indirectly, yet profoundly, we sometimes get the perspective of Pais himself, going well beyond personal recollections. During the description of Eugene Wigner's life, for example, the author admits to a difficulty in "grasping the personalities" of Hungarianborn physicists such as Leo Szilard, Edward Teller, John von Neumann (officially Margittai Neumann Janos Lajos) and, of course, Wigner himself. There is a quaint, lightly exotic something that sets the Hungarians apart from the more classic Mittel-European variety of the twentieth-century physicists who changed the world for ever.

There is a wider lesson, in history and sociology, to be learnt here, especially for younger readers. Of the 17 biographies in Pais' book, 13 are of European-born (and educated) scientists. Some, such as Isidor Rabi, are from countries like Galicia, which shifted from being a province of the AustroHungarian Empire to becoming part of postSecond World War Poland; some, like Pauli, simply say "I am European".

Pauli had his reasons. He was born and educated in Vienna, studied in Munich, was appointed ETH-Zürich full professor at 28, became, by default, German after the Anschluss (1933), but, in 1938, was denied Swiss citizenship because of his insufficient knowledge of "Schwitzerdeutch" (while, of course, his Hochdeutch was impeccable). Yet, after the war and the Nobel prize, he turned down lucrative appointments in the United States to come back to Zürich and, finally, to become a Swiss citizen. Of the other Pais personae, two are Chinese-born (Tsung Dao Lee and Chen Ning Yang), and only two, Mitchell Feigenbaum and Robert Serber, were born in the United States.

What better way to depict, besides the lives and science of the famed, the twentieth-century wave of migration of European culture towards the United States. This was a phenomenon of staggering proportions and extent. A different, but also very interesting, account of the same global phenomenon is in a lesser-known book by Laura Fermi, Illustrious Immigrants (University of Chicago Press, 1968), which includes physicists, of course, but ranges also to other sciences, and to music and the arts.

In covering a wide range of topics, from relativity to chaos theory, Pais' life-andscience stories provide, above all, the staple on which young (and not so young) scientists should feed their ambitions. Alternatively, we can just enjoy and be enriched, both culturally and emotionally.

Giovanni F. Bignami is at the Agenzia Spaziale Italiana, Viale Liegi 26, 00198 Rome, Italy.

\section{n......................... Wacky star of the Renaissance}

\section{Cardano's Cosmos: The Worlds and Works of a Renaissance Astrologer \\ by Anthony Grafton \\ Harvard University Press: 2000. 284 pp.

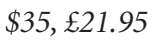

\section{Owen Gingerich}

Girolamo Cardano was seen by his 1950s biographer, Oystein Ore, as "the gambling scholar", the man who introduced ideas of probability to Western civilization. Cardano's Ars Magna, the book containing the general solution of the cubic equation and generally seen as the greatest mathematical treatise of the sixteenth century, has been characterized as the first decisive advance over the attainments of the giants of classical Greek mathematics. The Dictionary of Scientific Biography lists medicine as the first of Cardano's qualifications and declares that among the physicians of Europe, he ranked second only to Vesalius. Yet another Cardano emerges in this new book: the leading astrologer of his day, rivalled only by Luca Gaurico and later by the Elizabethan magus John Dee.

It was no doubt inevitable that historian Anthony Grafton would bring his formidable intellect and lucid style to bear on Cardano. The Princeton professor has already completed a magisterial, two-volume study of the great Renaissance classical scholar Joseph Scaliger, whose father's greatest claim to fame was, in Grafton's words, "the most savage book review in the bitter annals of literary invective", a 900-page rebuttal of Cardano's On Subtlety.

Born in Italy in 1501, Cardano set out on the path to becoming Europe's most famous astrologer with the publication of an accessible astrological handbook in 1538. Five years later he achieved international notoriety when it was reissued as Libelli Duo in an enlarged version with 66 genitures, or birth horoscopes, of notable people. The book was

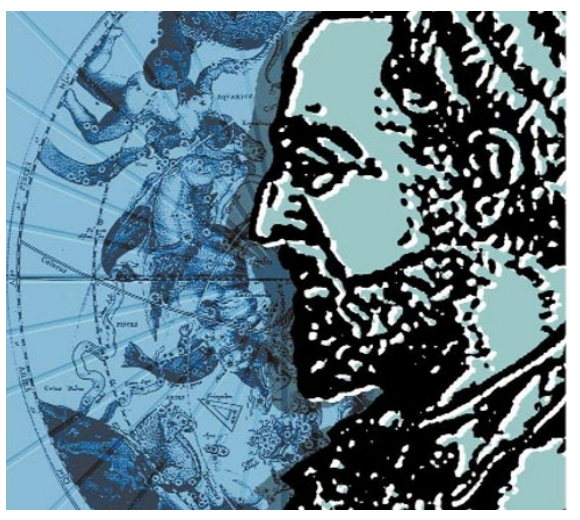

widely circulated, perhaps as much for its gossip and character assessments of the rich and famous as for its astral clues. That was in 1543, the year that the same publisher Johannes Petreius of Nuremberg — brought out Copernicus's De Revolutionibus.

Two years later Petreius printed Cardano's most enduring book, his Ars Magna, an event off Grafton's map, although he does include a great deal of other fascinating information about the Nuremberg publisher. In 1547 Cardano produced a further expanded book of genitures, now Libelli Quinque.

Cardano's astrological publications had a variety of consequences. Now a controversial figure, he also became a sought-after adviser who could both prescribe medicine and deliver prognostications. He lived in a world of contradictions, where the messages from medicines and from the stars were fraught with ambiguity. It is this complex world of Renaissance growing pains that Grafton carefully dissects, with all its mixed signals and complexities. And he does it with literary grace and marvellous turns of phrase: "Cardano promised those who walked the paper corridors of his collection the secrets of both natural and political power". His acquaintance Rheticus, Copernicus's only disciple, was none too pleased at being portrayed - in Grafton's vivid description - "as Dr Watson to Cardano's astrological Mr Holmes". In an "unbuttoned" autobiography Cardano portrayed himself as a "wacky professor", Grafton writes, considering this "a partial mirror of his fractured self".

Elsewhere, Grafton has written engagingly on the history of the footnote; here he reveals himself to be an erudite master of endnotes. A rich array of esoteric sources never hinders the narrative, but provides the evidence at the end of the volume. And when the desired materials aren't available from Cardano, because his letters had been burned, Grafton switches effortlessly to a well-documented case of how to give economic advice to clients by the infamous seer Nostradamus. Only very rarely can one catch Grafton out. During a meeting with John Dee in 1552, when Cardano had come 